\title{
Echo chambers revisited: The (overwhelming) sharing of in-group politicians, pundits and media on Twitter
}

\author{
Magdalena Wojcieszak $^{\mathrm{a}, \mathrm{b}},{\text { Andreu } \text { Casas }^{\mathrm{c}}, \text { Xudong Yu }^{\mathrm{a}} \text {, Jonathan Nagler }}^{\mathrm{d}}$, and Joshua A. Tucker \\ ${ }^{\mathrm{a}}$ University of California-Davis; ${ }^{\mathrm{b}}$ University of Amsterdam; ${ }^{\mathrm{c}}$ Free University of Amsterdam; ${ }^{\mathrm{d}}$ New York University
}

This manuscript was compiled on January 12, 2021

\begin{abstract}
Analyzing four years of data from a random sample of about $1.5 \mathrm{mil}-$ lion Twitter users (and about 180,000 politically engaged users), we revisit the debate regarding the extent to which social media users live in political "echo chambers" with two new analytic approaches. First, we focus on the sharing of content from political elites, arguably the most influential and politically active actors, and estimate the extent to which ordinary users share messages from politicians, pundits, and news media of the same versus opposing ideology. Second, we examine the extent to which this sharing is annotated by users before it is shared ("quoted retweets") and the tone of these annotations (e.g., do users share out-group content with negative commentary?). We find clear patterns indicative of echo-chambers: the politically engaged users analyzed share in-group messages from elites 14 times more frequently than out-group messages; and in the rare instances when out-group information is shared, a non-trivial amount of times it is accompanied by negative comments. These patterns emerge after accounting for how many in-group versus outgroup elites a person follows, and are robust to the political interest of the user or extremity of the elite accounts, the topic of the tweet, and the type of political elite source of the original message. In line with previous research, we also find that this echo chamber is especially pronounced among conservative users, who are about twice as likely as liberals to share in-group vs out-group content. These findings have important implications for how we theorize and study online echo chambers.
\end{abstract}

Social media | Echo chambers | Political Polarization | Computational social science

\section{Introduction}

2 Social media platforms are fast becoming a primary source of political information for a growing number of citizens $(1,2)$. This profoundly shifts the ways users encounter news, increases the amount of content available, and places individuals in unique media environments characterized by information flows curated by the users themselves and filtered through their social contacts. Although these changes in consumption patterns can facilitate exposure to diverse perspectives and connections with people holding different political views, they can also lead to the emergence of echo chambers, in which users see, consume, and share information that is consistent with their political views and communicate with other members of their partisan or ideological in-group $(3,4)$.

The debate over the prevalence of social media echo chambers is inconclusive (5), which is surprising given its immense importance for democracy. Exposure to congenial content and interactions with one's political in-group are feared to fuel extremity, exacerbate hostility between different factions, and ultimately thwart consensual governance (4, 6-8). Studies show that some groups inhabit algorithmically curated echo chambers (9), the online blogosphere is ideologically divided $(10,11)$, and social media users discuss politics with those who share their predispositions (12). Yet, others suggest that opposing partisans largely follow the same political accounts on social media (13) and discussions about non-political topics occur across party lines (12). The extent of ideological asymmetries in potential echo chambers is also unclear: sometimes liberals are found to have more like-minded connections than conservatives (13), other times they are shown to engage in greater cross-ideological communication $(6,12)$.

We contribute a new approach to assessing the prevalence of social media echo chambers by focusing on the sharing of information produced by political elites - arguably the most influential and politically active users - and proposing a novel approach to measuring information flows on social media with the aim of better estimating the prevalence and the precise nature of echo chambers. We focus on the active role of individual users in the creation and propagation of echo-chambers by means of sharing information from in-group political elites. Politicians, pundits, and media contribute the overwhelming majority of political content and dominate political discussions on social media (14). Furthermore, elite communication is central to the attitudes and behaviors of the electorate and can play into exacerbating polarization

\section{Significance Statement}

We provide a crucial new perspective to the debates regarding the existence of echo chambers by (a) examining the spread of elite generated content online and (b) assessing user annotations of that content. Using a random sample of US politically engaged Twitter users, we estimate the extent to which users share information from in-party versus out-party elites, and whether any commentary on the shared messages takes a neutral, positive, or negative tone. We find clear evidence of echo chambers: users share in-group elite content 14 times more frequently than out-group elite content, with a non-trivial amount of users adding negative comments to the latter. These patterns are robust across issues, and especially pronounced among conservatives. These findings have important implications for our understanding of online echo chambers.

M.W., X.Y, and A.C. designed research; J.T. and J.N. oversaw the data collection, A.C. contributed the classifiers/analytic tools; A.C. and X.Y. analyzed data; and M.W. and A.C. wrote the first draft of the paper, and all of the authors contributed to revising the manuscript.

The authors declare no conflict of interest.

1: M.W. and A.C. contributed equally to the paper

2 E-mail: mwojcieszakucdavis.edu 
46 (6). Elite cues can distort citizens' policy preferences (15-17) 4 and - by making interparty divisions clearer - polarize their 48 attitudes $(15,18)$. Elite communication also makes people's 4 partisan identities more salient and casts politics as an usversus-them conflict, intensifying out-group hostility $(6,19)$. Insular sharing of elite messages can feed into perceptions of polarization, even among people who are not active on social media (e.g., via traditional media (20)), ultimately exacerbating actual polarization (21). Therefore, accounting for how ordinary social media users share elite messages is not only needed to provide an accurate picture of echo chambers, but also has important societal implications.

The phenomenon of active sharing is also important because it affords users a subtle, yet powerful, strategy to exacerbate echo-chambers: users can not only share messages but also accompany them with commentary. This crucial affordance of social media, key to the debate on echo chambers, remains unstudied at scale. Theoretically, popular psychological frameworks establish that once individuals identify with a group, they aim to enhance its identity by positively distinguishing themselves and their in-group from the out-group $(22,23)$. In the context of partisan communication online, this need for distinctiveness can be met by sharing content supportive of one's in-group with positive commentary. However, another way to enhance in-group identity is derogate the out-group (24). It may be the case that users do share information from across the political aisle, but do so to criticize the message or its source (e.g., liberals sharing Trump's tweets to mock the President). Although this phenomenon is visible in partisan media, which 'praise' the preferred political faction (25) while also attacking the opposition $(26,27)$, it has been overlooked in the online environment. Yet assessing the sentiment of the comments users add to the shared elite information offers a more complete picture of potential echo chambers.

To examine whether and how users share information from in- versus out-group political elites (i.e., politicians, pundits, and news media), we rely on four years of data (2016-2019) from a random' sample of about 1.5 million Twitter users and look for instances in which they shared or quoted tweets from over 2,500 American elite accounts, which results in about 30 million retweets in total. After using a validated method for estimating the ideology of regular and elite accounts (12) and a Convolutional Neural Network for classifying the sentiment of the quotes (28), we use these data to address three progressively specific question about the role of ordinary users in actively exacerbating echo chambers: (1) what is the proportion of in-group versus out-group elite information shared by users, (2) what is the sentiment - positive, neutral, or negative - of the comments added to in-group versus outgroup information, and (3) are there ideological asymmetries in these behaviors (e.g., are liberals or conservatives more likely to share messages from across the aisle or accompany them with positive/negative comments)?

This approach advances prior work, which has largely focused on measures of passive exposure, i.e., whether users see information from within or across the political aisle (e.g., do liberal Twitter users follow conservative accounts? Are conservatives exposed to news shared by liberals on Facebook? $(10,11,13,29))$. While at least one study explored the more active behavior of cross-ideological retweeting (12), the study did not address the retweeting of political elites explicitly - instead examining all users - nor did the study account for the potential of negative annotation accompanying retweets.

Putting information generated by political elites at the center of the analysis yields a very clear picture of echo chambers. In our sample, tweets from in-group elites are shared overwhelmingly more frequently than tweets from out-group elites (at about a 14:1 ratio). Indeed, the sharing of out-group elite is extremely limited: $7 \%$ of the tweets in our sample. Moreover, the sentiment of the comments on out-group tweets works to reinforce the ideological bubble: quote tweets (or the added commentary) not only constitute a much larger percentage of out-group than in-group shares $(1 / 3 v .1 / 10)$ but also are negative a quarter of the time when accompanying out-group tweets. In sum, across our 30 million retweets of elite content, only $5 \%$ were retweets of out-group elites without any negative commentary. These patterns hold when accounting for the proportion of in-group versus out-group elites followed (i.e., users share in-group elites not only because they follow them more), across elite actors (although the sharing of politicians points to a clearer echo chamber) and numerous issues, ranging from the economy to civil rights. We also find important ideological asymmetries: conservative users are roughly twice as likely as liberals to share in-group vs. out-group content, as well as to add negative commentary to shares of out-group politicians, pundits, and partisan media.

We note, as detailed below, that these patterns apply to politically active Twitter users, who are a subset of the overall Twitter and American populations. The majority of Americans do not share political information online (14), and many - as we show - follow no political accounts on Twitter. Also, $10 \%$ of most active Twitter users produce $80 \%$ of all tweets created by all U.S. users; and this top $10 \%$ is also more likely to tweet about politics (30). As such - naturally - the detected echo chamber does not apply to the overall population. Yet, the group inhabiting the echo chamber we observe, although a small proportion of overall users, are disproportionately active in the political process, online and offline (31).

\section{Results}

To quantify the active sharing echo chamber, we tracked the messaging activity of a random sample of 1,437,774 Twitter users for four years (2016-2019). ${ }^{*}$ We looked for tweets quoting (i.e., retweets with a comment) or retweeting (i.e., tweets shared without any commentary) an exhaustive set of 2,621 political actors (488 politicians, 2,016 pundits, and 116 media organizations), a total of $33,177,369$ shares. In order to establish whether these users shared tweets from their political in-group or out-group, we used Barbera's (12) validated Bayesian Spatial Following model for estimating on the same continuous scale the ideological positions of political elites and ordinary Twitter users. About $40 \%$ of the users $(580,921$ out of $1,437,774$ ) followed at least one of the political elites, and $13 \%$ followed enough elite accounts for us to calculate an ideology score $(181,549$ out of $1,437,774)$. We study the users in this group that shared at least one elite tweet $(180,203$

\footnotetext{
*We generated the random collection in two ways. (a) First, before Twitter switched to 64-bit IDs in 2016, we automatically generated 32-bit random numbers and checked for whether they were existing Twitter users. (b) Then, after the introduction of the longer Twitter IDs, we increased the size of the sample: we collected tweets mentioning a set of English stopwords (i.e. "the") for numerous short amounts of time selected at random, then we pulled the authors of those tweets and information about how frequently they tweeted, and we subsampled a set of authors with a tweeting distribution similar to that of the users in the list created using method (a).
} 


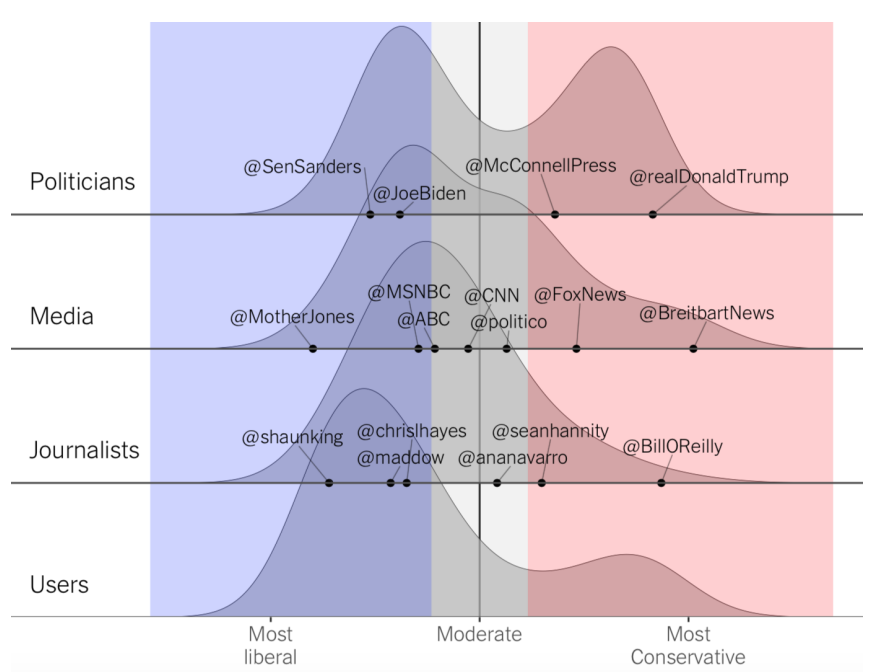

Fig. 1. Distribution of the estimated ideology of the actors and ordinary users we study.

users). Despite representing a small proportion of the full random sample of users (13\%), this group accounts for most of the shares of elite tweets we collected $(86 \%-28,561,739$ out of 33,177,369 shares), and thus can help us understand the vast majority of the elite sharing behavior.

To distinguish when users shared messages from out- versus in-group elites, we split the continuous ideology scale into a liberal, moderate, and conservative space, and classified the accounts accordingly. Figure 1 shows the distribution of the ideology of the elites and ordinary users and the face validity of our measure. We focus on liberal and conservative elites and ordinary users (i.e., the blue and red areas in Figure 1), excluding moderates, for whom a clear political in-group and out-group cannot be determined (1,718 elite accounts and 155,626 ordinary users). ${ }^{\dagger}$ SI 4 shows that our findings hold when including and classifying moderates into liberals and conservatives (using the vertical line in Figure 1 as cut-off point).

In order to establish the sentiment of the commentary accompanying quote tweets, we manually annotated a random sample of quotes for whether they were negative, neutral or positive toward the original tweet, ${ }^{\ddagger}$ and we used them to train a Convolutional Neural Net (CNN) to predict the tone of the remaining quotes (see SI8). The findings are robust to using tone predictions generated by alternative machine learning models (a Support Vector Machine and an Ensemble of several ngram-based models, see SI3 ).

First, we explore the presence and size of echo chambers by looking at how often users share content from in-group $v$. outgroup politicians, pundits, and media (Figure 2). We find clear evidence of echo chambers. Of all political elite tweets users share (with or without commentary), over $90 \%$ are from elites consistent with their ideology. Users are dramatically more likely to simply retweet - without commentary - messages from in-group than from out-group elite accounts. In general,

\footnotetext{
${ }^{\dagger}$ Politicians: 193 liberal accounts, 82 moderate, and 213 conservative ones (488 in total). Media: 51 liberal, 39 moderate, 27 conservative (117 in total). Pundits: 969 liberal, 782 moderate, 265 conservative (2,016 in total). Users: 119,670 liberal, 24,577 moderate, 35,956 conservative $(180,203$ in total).

${ }^{\ddagger}$ Assistants annotated 8,351 tweets for their stance (Krippendorff’s alpha= .816 ) toward the message and/or the political actor, independently of the tone of the original message.
}

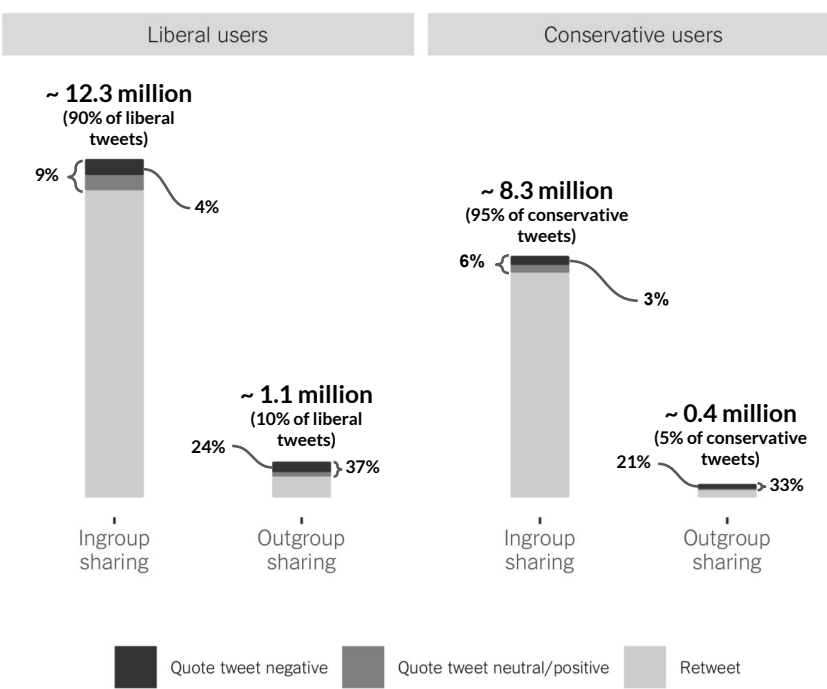

Fig. 2. How often ordinary users share (retweet $v$. quote tweet) messages from in-group $v$. out-group elites.

for every out-group tweet a user shares, the user shares (with or without commentary) around 14 tweets from the in-group elite. The same overall pattern emerges across elite actors, although users are more likely to share tweets from in-group (rather than out-group) media and pundits than politicians (see SI5). The levels of in-group sharing are also very high (although not as high) among users with low ideological extremity, indicating that echo chambers are not merely a function of a few extreme users sharing information from few extreme elite sources.

Clear ideological asymmetries emerge. Although in-group elite content represents similar (overwhelmingly large) proportion of all elite sharing by conservative (95\%) and liberal (90\%) ordinary users, Figure 2 shows that the ratio of out-group to in-group shares is dramatically different: 11:1 for liberals (12.3 mln in-group/1.1 mln ougroup shares) and 21:1 for conservatives $(8.3 \mathrm{mln}$ in-group $/ 0.4 \mathrm{mln}$ out-group). Compared to liberal users, conservatives share in-group over out-group elite content at a much higher rate. This cannot be explained by conservative users following fewer out-group accounts. In absolute terms, on average conservatives follow 3.25 out-group elites (95\% CI: 3.17-3.32) and liberals 2.53 (95\% CI: 2.51-2.56). In relative terms, out-group elites represent a similar proportion of all elite accounts followed by conservative (11.3\% [95\% CI: 11.2-11.5]) and liberal users (12.8\% [95\% CI: 12.7-12.9]).

To offer more stringent evidence, we estimated a logistic regression model predicting the likelihood that users share ingroup versus out-group elite tweets, as a function of the type of the elite (politicians, pundits, news media), the ideological extremity of the actor, ${ }^{\S}$ the ideology of the user (liberal versus conservative), and the number of out-group elite accounts followed by each user (see SI1 for point estimates and $95 \%$ CIs). Figure 3, which plots the marginal effects, shows lower ingroup sharing rates for politicians than the pundits, indicating that tweets by out-group politicians are more likely to be shared (likely to be criticized, as noted below). Also, the more extreme the political actor, the more likely their tweets are to be shared by in-group users, suggesting the appeal

$\S$ Their folded continuous ideology score obtained using Barbera's ((12)) method. 


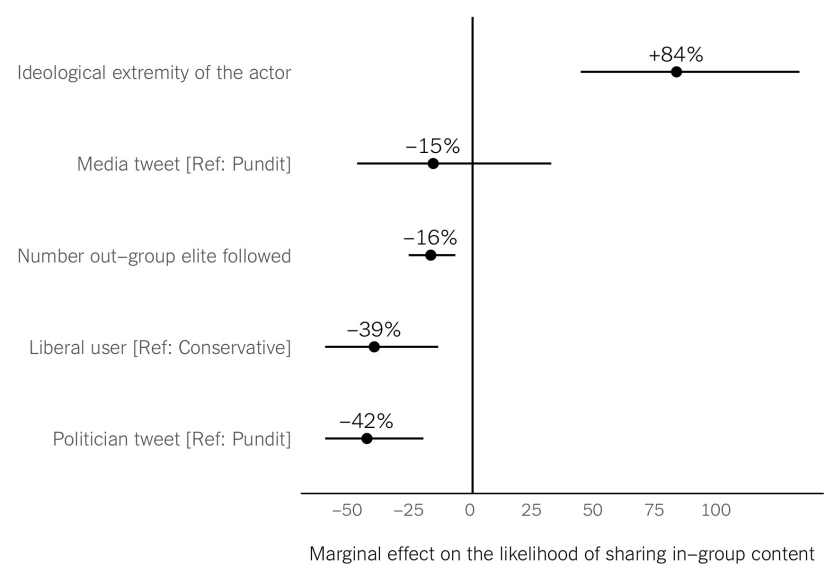

Fig. 3. Marginal effects, on in-group sharing, of the elite account being a politician or media (v. pundit), the ideological extremity of the elite actor, the ideology of the ordinary users, and the number of out-group elite accounts a users follows. For continuous variables (ideological extremity and number of out-group elites followed) we report the marginal effect of a one standard deviation change.

of polarizing content and elites. Furthermore, compared to conservative users, liberals are $39 \%$ less likely to share tweets from in-group elites, even after controlling for these potential confounders, in line with the findings in Figure 2.

The extent and the nature of this active sharing echo chamber is further contingent on the sentiment of the commentary added to the shared messages. Examining the decision to comment in the first place, ${ }^{\top}$ we find that ordinary users add comments at a higher rate when sharing out-group tweets (37\% for liberals; $33 \%$ for conservatives) than when sharing in-group messages ( $9 \%$ and $6 \%$ respectively) (see Figure 2), suggesting that many users retweet out-group content to express their stance (rather than endorse uncritically, as for in-group content). Additionally, the machine learning sentiment predictions find that relative to all messages shared, both liberals and conservatives are substantially more likely to add a negative comment to an out-group tweet (24\% of all out-group shares for liberals; $21 \%$ for conservatives) than to an in-group tweet (4\% of all in-group shares for liberals; $3 \%$ for conservatives). This translates into users adding negative commentary to a tweet from an out-group elite 6 times (liberals) and 7 times (conservatives) more often than to a tweet from an in-group elite. In short, on the rare occasions users share commentary on tweets from across the aisle, they do so to promote the in-group perspective, with $63 \%$ of all quote tweets from the out-group shared with negative annotation.

To better understand the conditions under which users comment on out-group messages, we estimated a set of ordinal logistic regression models predicting the sentiment of the comments on the shared tweets, as a function of whether the retweet was from an in-group vs. an out-grup elite, as well as all the covariates included in the models above. In Figure 4 we report the results of six models (see SI2 for the coefficient tables). The top panel depicts the results for a model including all quote tweets. Even after accounting for potential

I After removing quote tweets too short for sentiment predictions ( $<5$ words), the final sample for these analyses is $1,519,943$ tweets sent by 86,597 users (about $50 \%$ of the 180,203 politically active users) quoting 1,669 elites: $576,529(38 \%)$ tweets quoting 402 politicians, $404,429(27 \%)$ quoting 78 media organizations, and 538,985 (35\%) quoting 1,189 pundits. In general, 704,840 (46.37\%) quoted conservative actors and $815,103(53.63 \%)$ quoted liberal actors.

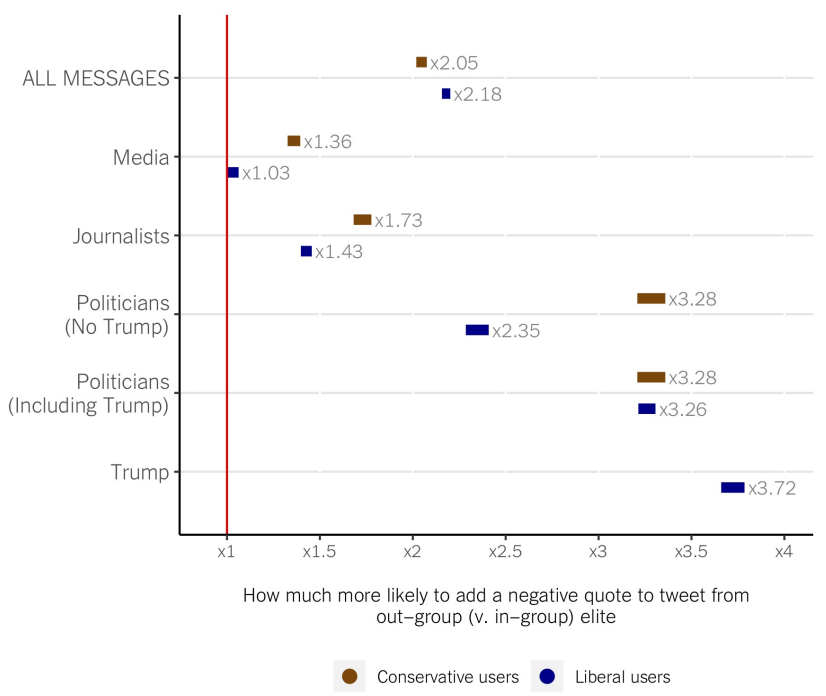

Fig. 4. Multinomial models predicting the likelihood of attaching negative comments when sharing tweets from out-group ( $v$. in-group) elite accounts.

confounders, a tweet of an out-group vs. in-group political actor is substantially more likely to be shared with a negative vs. a neutral or positive comment. These patterns emerge among liberals and conservatives alike (2.18 times more likely for liberals, and 2.05 times for conservatives).

The panels below show that the type of elite actor whose information is shared, and also users' ideology, matter. On average, tweets from out-group politicians are most likely to be shared with a negative commentary, followed by outgroup pundits and media accounts. Despite the aggregate similarity, conservatives are more likely than liberals to add negative comment to retweets from out-group politicians (3.28 times more likely $v$. 2.35), journalists (1.73 v. 1.43), and especially out-partisan media (1.36; liberals are only $3 \%$ more likely to negatively comment on out- than on in-group media retweets). Quote tweets of President Trump are the reason for the aggregate similarity between liberals and conservatives: these tweets represent a large portion of the quote tweets in our dataset (around 20\%) and liberal users are overwhelmingly likely to share them with negative comments. These models are robust to employing tone/sentiment predictions made by alternative machine learning models (see SI3 ).

Lastly, to assess whether these patterns depend on specific topics (e.g., when elites discuss divisive and hot-button issues versus complex policies), we trained a Convolutional Neural Net $(\mathrm{CNN})$ to predict the presence of topics from the Comparative Agendas Project in the tweets (see SI9) and estimated multinomial models predicting the sentiment of the commentary attached to quote tweets about each topic, independently of the type of actor. The echo chambers are reinforced with negative commentary on divisive issues in American politics, such as immigration or civil rights, more than on the technical ones, such as technology or transportation. Yet, with a couple isolated exceptions, users from both ideologies are always more likely to add a negative comment to out-group rather than in-group messages (see Figure 5). 


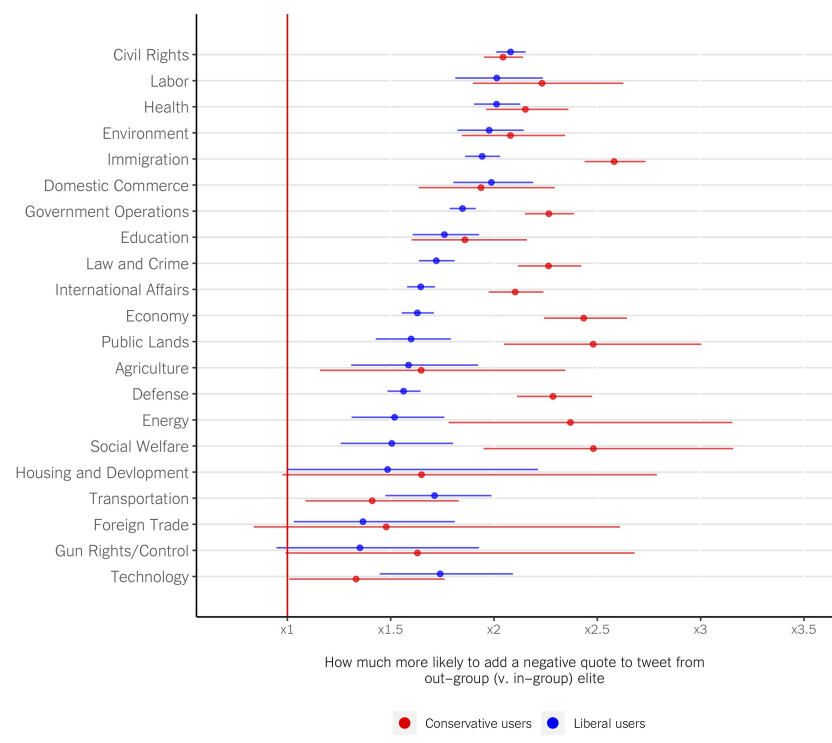

Fig. 5. Multinomial models predicting the likelihood of attaching negative comments when sharing tweets from out-group ( $v$. in-group) elite accounts, for each of the policy areas discussed in the original elite tweets.

adding negative comments to these shares. This behavior is particularly pronounced when sharing out-group politicians. Also, when we exclude tweets from Donald Trump, we find that conservatives negatively comment on tweets from out-group elites more often than liberals. Because, however, liberals often share and criticize Trump's tweets, including them yields similar aggregate effects for both ideological groups.

Attending to the echo chambers created when users share information from political elites and to the annotations on these shares extends the ways in which researchers can - and should - study online communication. Users do exacerbate echo chambers not only by sharing in-group elite messages but also by facilitating anti-out-group interpretation by mocking out-group information or ridiculing its source.

Although ours is among the most systematic examinations of how social media users share elite content and how they annotate it with their comments, the findings should not be interpreted as generalizing to the full US population. A majority of Americans do not use Twitter and those who do are not representative of the population. That said, those politically active on Twitter are also politically active offline (34) and shape public discussion in mainstream media (20) Furthermore, the majority of social media users do not post about politics, and our project under-represents this population. Facebook estimates that news content accounts for about $4 \%$ of overall content on the platform (35) and other work finds that over a third of Twitter users do not follow any media sources (13). As such, we may overestimate the prevalence of echo chambers. It is crucial to emphasize, however, that those apolitical citizens are not the focus of the debates on echo chambers (after all, if one does not engage with politics, one cannot engage with politically congenial or cross-cutting frames), and - even if they were - they cannot be studied (i.e., their political in-group or out-group cannot be determined by trace data and surveys that link individual self-reports to online behaviors rarely allow for such large-scale investigations as ours). Furthermore, the clear echo chambers persisted when we analyzed ideologically moderate (although still politically engaged) Twitter users.

Despite these limitations, our findings have key implications for research and democracy at large. When we witness a growing radicalization of certain groups in American society (and globally) and the New York Times claims that "The storming of Capitol Hill was organized on social media"," concerns about echo chambers and their effects become ever more pressing. Observers worry that users connect with likeminded others and encounter reinforcing information. Our findings lend credence to these worries, showing that the actions of ordinary users create and perpetuate echo chambers on social media. Although users may discuss sports or natural disasters with out-partisans (12) or follow similar elite accounts (13), the ways in which people share and engage with content from the most influential political elites are as - if not more important as who they follow.

\section{Materials and Methods}

See SI Appendix for a detailed description of all materials and methods used within this study as well as additional robustness checks extended discussion of the used classifiers as well as alternative

" ${ }_{\text {https://www.nytimes.com/2021/01/06/us/politics/protesters-storm-capitol-hill-building.html }}$ 
classifications. The data and the code will be made available upon publication on GitHub and on Dataverse.

ACKNOWLEDGMENTS. The Center for Social Media and Politics at New York University is supported by funding from the John S. and James L. Knight Foundation, the Charles Koch Foundation, Craig Newmark Philanthropies, the William and Flora Hewlett Foundation, the Siegel Family Endowment, the Bill and Melinda Gates Foundation, and the National Science Foundation.

1. R Fletcher, RK Nielsen, Are people incidentally exposed to news on social media? A comparative analysis:. New Media \& Soc. (2017).

2. A Geiger, Key findings about the online news landscape in America (2019).

3. E Pariser, The Filter Bubble: How the New Personalized Web Is Changing What We Read and How We Think. (Penguin Books), Reprint edition edition, (2012).

4. CR Sunstein, \#Republic: Divided Democracy in the Age of Social Media. (Princeton University Press, Princeton, N.J. Oxford), Updated edition edition, (2018).

5. Pablo Barbera, Social Media, Echo Chambers, and Political Polarization in Social Media and Democracy: The State of the Field, Prospects for Reform, eds. N Persily, JA Tucker. (Cambridge University Press, Cambridge), (2020).

6. EJ Finkel, et al., Political sectarianism in America. Science 370, 533-536 (2020) Publisher: American Association for the Advancement of Science Section: Policy Forum.

7. MJ Hetherington, TJ Rudolph, Why Washington Won't Work: Polarization, Political Trust, and the Governing Crisis. (University of Chicago Press), Illustrated edition edition, (2015).

8. S lyengar, Y Lelkes, M Levendusky, N Malhotra, SJ Westwood, The origins and consequences of affective polarization in the united states. Annu. Rev. Polit. Sci. 22, 129-146 (2019).

9. Y Benkler, R Faris, H Roberts, Network Propaganda: Manipulation, Disinformation, and Radicalization in American Politics. (Oxford University Press), (2018) Google-Books-ID: MVRuDWAAQBAJ.

10. LA Adamic, N Glance, The political blogosphere and the 2004 US election: Divided they blog in Proceedings of the 3rd International Workshop on Link Discovery. (ACM, New York), pp. $36-43$ (year?).

11. E Lawrence, J Sides, H Farrell, Self-segregation or deliberation? blog readership, participation, and polarization in american politics. Perspectives on Polit. 8, 141-157 (2010).

12. P Barberá, JT Jost, J Nagler, JA Tucker, R Bonneau, Tweeting From Left to Right: Is Online Political Communication More Than an Echo Chamber? Psychol. Sci. (2015) Publisher: SAGE PublicationsSage CA: Los Angeles, CA.

13. G Eady, J Nagler, A Guess, J Zilinsky, JA Tucker, How Many People Live in Political Bubbles on Social Media? Evidence From Linked Survey and Twitter Data. SAGE Open 9 , 2158244019832705 (2019) Publisher: SAGE Publications.

14. P Barberá, et al., Who Leads? Who Follows? Measuring Issue Attention and Agenda Setting by Legislators and the Mass Public Using Social Media Data. Am. Polit. Sci. Rev. 113, 883901 (2019) Publisher: Cambridge University Press.

15. JN DRUCKMAN, E PETERSON, R SLOTHUUS, How Elite Partisan Polarization Affects Public Opinion Formation. The Am. Polit. Sci. Rev. 107, 57-79 (2013) Publisher: [American Political Science Association, Cambridge University Press].

16. KJ Mullinix, Partisanship and Preference Formation: Competing Motivations, Elite Polarization, and Issue Importance. Polit Behav 38, 383-411 (2016).

17. SP Nicholson, Polarizing Cues. Am. J. Polit. Sci. 56, 52-66 (2012) eprint: https://onlinelibrary.wiley.com/doi/pdf/10.1111/j.1540-5907.2011.00541.x.

18. M Levendusky, How Partisan Media Polarize America. (University of Chicago Press, Chicago ; London), Illustrated edition edition, (2013).

19. M Levendusky, N Malhotra, Does Media Coverage of Partisan Polarization Affect Political Attitudes? Polit. Commun. 33, 283-301 (2016) Publisher: Routledge _eprint: https://doi.org/10.1080/10584609.2015.1038455.

20. SC McGregor, L Molyneux, Twitter's influence on news judgment: An experiment among journalists. Journalism 21, 597-613 (2020) Publisher: SAGE Publications.

21. MS Levendusky, N Malhotra, (Mis)perceptions of Partisan Polarization in the American Public. Public Opin Q 80, 378-391 (2016) Publisher: Oxford Academic.

22. H Tajfel, Social Psychology of Intergroup Relations. Annu. Rev. Psychol. 33, 1-39 (1982) _eprint: https://doi.org/10.1146/annurev.ps.33.020182.000245.

23. Henri Tajfel, John Turner, An Intergrative Theory of Intergroup Conflict in Organization Identity: A Reader, eds. Mary Jo Hatch, Majken Schultz. (Oxford University Press), pp. 56 - 66 (1979).

24. Marilynn B. Brewer, Ingroup Identification and Intergroup Conflict in Social Identity, Intergroup Conflict, and Conflict Reduction, eds. RD Ashmore, Lee Jussim, David Wilder. (Oxford University Press), pp. $17-41$ (2001).

25. MA Baum, T Groeling, Shot by the Messenger: Partisan Cues and Public Opinion Regarding National Security and War. Polit Behav 31, 157-186 (2009).

26. R Puglisi, JM Snyder, Newspaper Coverage of Political Scandals. The J. Polit. 73, 931-950 (2011) Publisher: The University of Chicago Press.

27. JM Berry, S Sobieraj, The Outrage Industry: Political Opinion Media and the New Incivility. (Oxford University Press), (2013).

28. Y Kim, Convolutional neural networks for sentence classification (2014).

29. E Bakshy, S Messing, LA Adamic, Exposure to ideologically diverse news and opinion on Facebook. Science 348, 1130-1132 (2015) Publisher: American Association for the Advancement of Science Section: Report.

30. S Wojcik, A Hughes, Sizing up twitter users. Washington, DC: Pew Res. Cent. (2019).

31. Al Abramowitz, KL Saunders, Is polarization a myth? The J. Polit. 70, 542-555 (2008).

32. JA Tucker, et al., Social Media, Political Polarization, and Political Disinformation: A Review of the Scientific Literature, (Social Science Research Network, Rochester, NY), SSRN Scholarly Paper ID 3144139 (2018).
33. JT Jost, J Glaser, AW Kruglanski, FJ Sulloway, Political conservatism as motivated social cognition. Psychol. Bull. 129, 339-375 (2003).

34. D Freelon, A Marwick, D Kreiss, False equivalencies: Online activism from left to right. Science 369, 1197-1201 (2020) Publisher: American Association for the Advancement of Science Section: Review.

35. M Zuckerberg, Facebook (2018). 
Supporting information for

\section{Echo chambers revisited: The (overwhelming) sharing of in-group politicians, pundits and media on Twitter}

Magdalena Wojcieszak* $^{*}$ Andreu Casas ${ }^{\dagger} \quad$ Xudong $\mathrm{Yu}^{\ddagger} \quad$ Jonathan Nagler $^{\S}$ Joshua Tucker

* University of California, Davis \& University of Amsterdam

${ }^{\dagger}$ Free University of Amsterdam

$\ddagger$ University of California, Davis

$\S$ New York University

『New York University 


\section{Contents}

1 Logistic regression model predicting the likelihood that users share in-group versus outgroup elite tweets

2 Ordinal logistic regression models predicting the sentiment of the comments on the shared tweets

3 Ordinal logistic regression models predicting the sentiment of the comments on the shared tweets using SVM and Ensemble

4 Ordinal logistic regression models predicting the sentiment of the comments on the shared tweets including moderates

5 Ingroup and outgroup sharing patterns by elite type $\quad 7$

6 Ingroup sharing and ideological extremity of the actors 9

7 Ingroup sharing and ideological extremity of the users $\quad 11$

8 Sentiment classifier $\quad 12$

9 Topic classifier $\quad 13$ 


\section{Logistic regression model predicting the likelihood that users share in-group versus out-group elite tweets}

Table 1.1: Logistic regression model predicting the likelihood that users share in-group versus out-group elite tweets

\begin{tabular}{llll}
\hline & pe & lwr & upr \\
\hline Ideological extremity of the actor & .84 & .45 & 1.34 \\
Media tweet [Ref: Pundit] & -.15 & -.46 & .33 \\
Number out-group elite followed & -.16 & -.25 & -.06 \\
Liberal user [Ref: Conservative] & -.39 & -.59 & -.13 \\
Politician tweet [Ref: Pundit] & -.42 & -.59 & -.19 \\
\hline
\end{tabular}

Note: pe $=$ point estimates. lwr $=$ lower bound of the $95 \%$ confidence interval. upr $=$ upper bound of the $95 \%$ confidence interval.

\section{Ordinal logistic regression models predicting the sentiment of the comments on the shared tweets}

Table 2.1: Ordinal logistic regression models predicting the sentiment of the comments on the shared tweets (Liberal users)

\begin{tabular}{lllllll}
\hline Variable & All Messages & Media & Journalists & $\begin{array}{l}\text { Politicians } \\
\text { (No Trump) }\end{array}$ & $\begin{array}{l}\text { Politicians } \\
\text { (Incl. Trump) }\end{array}$ & Trump \\
\hline Source (Out-group) & $-.78^{*}(.01)$ & $-.03^{*}(.02)$ & $-.36^{*}(.01)$ & $-.85^{*}(.01)$ & $-1.18^{*}(.01)$ & $-1.31^{*}(.01)$ \\
Num. Followers (actor) & $.04^{*}(.00)$ & $.03^{*}(.00)$ & $-.03^{*}(.00)$ & $-.00(.00)$ & $.06^{*}(.00)$ & - \\
Num. Friends (user) & $-.01^{*}(.00)$ & $-.01(.01)$ & $-.02^{*}(.01)$ & $-.04^{*}(.01)$ & $-.01^{*}(.00)$ & $-.00(.00)$ \\
Num. Followers (user) & $.06^{*}(.00)$ & $.06^{*}(.01)$ & $.03^{*}(.00)$ & $.05^{*}(.01)$ & $.06^{*}(.00)$ & $.06^{*}(.00)$ \\
Ideo. Extrimity (actor) & $-.53^{*}(.01)$ & $-.05(.03)$ & $-.23^{*}(.02)$ & $-.58^{*}(.04)$ & $-.67^{*}(.04)$ & - \\
Out. Elites Followed & $.00^{*}(.00)$ & $.00(.00)$ & $.00^{*}(.00)$ & $.00^{*}(.00)$ & $.00(.00)$ & $-.00(.00)$ \\
Negative | Neutral & $.48^{*}(.05)$ & $.63^{*}(.16)$ & $-.36^{*}(.13)$ & $-.69^{*}(.14)$ & $.49^{*}(.06)$ & $-.15^{*}(.07)$ \\
Neutral | Positive & $.57^{*}(.05)$ & $.73^{*}(.16)$ & $-.27^{*}(.13)$ & $-.59^{*}(.14)$ & $.58^{*}(.06)$ & $-.06(.07)$ \\
Controlling for Time & Yes & Yes & Yes & Yes & Yes & Yes \\
Controlling for Topic & Yes & Yes & Yes & Yes & Yes & Yes \\
\hline
\end{tabular}

Note: Number of actors' followers, number of users' friends, and number of a users' followers were $\log (x+1)$ transformed. Cell entries are regression coefficients with associated standard errors in parentheses. ${ }^{*} p<.05$ 
Table 2.2: Ordinal logistic regression models predicting the sentiment of the comments on the shared tweets (Conservative users)

\begin{tabular}{llllll}
\hline Variable & All Messages & Media & Journalists & $\begin{array}{l}\text { Politicians } \\
\text { (No Trump) }\end{array}$ & $\begin{array}{l}\text { Politicians } \\
\text { (Incl. Trump) }\end{array}$ \\
\hline Source (Out-group) & $-.72^{*}(.01)$ & $-.31^{*}(.01)$ & $-.55^{*}(.01)$ & $-1.19^{*}(.01)$ & $-1.19^{*}(.01)$ \\
Num. Followers (actor) & $.02^{*}(.00)$ & $.02^{*}(.00)$ & $-.01^{*}(.00)$ & $.02^{*}(.00)$ & $.02^{*}(.00)$ \\
Num. Friends (user) & $-.03^{*}(.00)$ & $-.01^{*}(.00)$ & $-.02^{*}(.00)$ & $-.04^{*}(.01)$ & $-.04^{*}(.01)$ \\
Num. Followers (user) & $.04^{*}(.00)$ & $.04^{*}(.00)$ & $.03^{*}(.00)$ & $.06^{*}(.01)$ & $.06^{*}(.01)$ \\
Ideo. Extrimity (actor) & $.24^{*}(.02)$ & $.33^{*}(.03)$ & $.15^{*}(.02)$ & $.46^{*}(.05)$ & $.46^{*}(.05)$ \\
Out. Elites Followed & $.00^{*}(.00)$ & $.00^{*}(.00)$ & $.00^{*}(.00)$ & $.00^{*}(.00)$ & $.00^{*}(.00)$ \\
Negative | Neutral & $.31^{*}(.06)$ & $.57^{*}(.08)$ & $-.17(.10)$ & $.32^{*}(.12)$ & $.32^{*}(.12)$ \\
Neutral | Positive & $.43^{*}(.06)$ & $.70^{*}(.08)$ & $-.04(.10)$ & $.41^{*}(.12)$ & $.41^{*}(.12)$ \\
Controlling for Time & Yes & Yes & Yes & Yes & Yes \\
Controlling for Topic & Yes & Yes & Yes & Yes & Yes \\
\hline
\end{tabular}

Note: Number of actors' followers, number of users' friends, and number of a users' followers were $\log (\mathrm{x}+1)$ transformed. Cell entries are regression coefficients with associated standard errors in parentheses. ${ }^{*} p<.05$

\section{Ordinal logistic regression models predicting the sentiment of the comments on the shared tweets using SVM and Ensemble}

Table 3.1: Ordinal logistic regression models predicting the sentiment of the comments on the shared tweets using SVM (Liberal users)

\begin{tabular}{lllllll}
\hline Variable & All Messages & Media & Journalists & $\begin{array}{l}\text { Politicians } \\
\text { (No Trump) }\end{array}$ & $\begin{array}{l}\text { Politicians } \\
\text { (Incl. Trump) }\end{array}$ & Trump \\
\hline Source (Out-group) & $-.62^{*}(.01)$ & $-.05^{*}(.02)$ & $-.33^{*}(.01)$ & $-.75^{*}(.01)$ & $-.91^{*}(.01)$ & $-.99^{*}(.01)$ \\
Num. Followers (actor) & $.04^{*}(.00)$ & $.02^{*}(.00)$ & $-.01^{*}(.00)$ & $-.00(.01)$ & $.07^{*}(.00)$ & - \\
Num. Friends (user) & $-.00(.00)$ & $-.03^{*}(.01)$ & $-.01(.01)$ & $-.03^{*}(.01)$ & $.00(.00)$ & $.01^{*}(.00)$ \\
Num. Followers (user) & $.01^{*}(.00)$ & $.04^{*}(.01)$ & $.01(.00)$ & $.01(.01)$ & $.00(.00)$ & $-.00(.00)$ \\
Ideo. Extrimity (actor) & $-.45^{*}(.01)$ & $-.15^{*}(.03)$ & $-.16^{*}(.02)$ & $-.85^{*}(.04)$ & $-.88^{*}(.04)$ & - \\
Out. Elites Followed & $.00^{*}(.00)$ & $.00(.00)$ & $.00^{*}(.00)$ & $.00^{*}(.00)$ & $.00^{*}(.00)$ & $.00^{*}(.00)$ \\
Negative | Neutral & $-.42^{*}(.05)$ & $-.41^{*}(.17)$ & $-1.19^{*}(.15)$ & $-1.39^{*}(.14)$ & $-.33^{*}(.07)$ & $-1.11^{*}(.07)$ \\
Neutral | Positive & $-.38^{*}(.05)$ & $-.36^{*}(.17)$ & $-1.15^{*}(.15)$ & $-1.35^{*}(.14)$ & $-.29^{*}(.07)$ & $-1.07^{*}(.07)$ \\
Controlling for Time & Yes & Yes & Yes & Yes & Yes & Yes \\
Controlling for Topic & Yes & Yes & Yes & Yes & Yes & Yes \\
\hline
\end{tabular}

Note: Number of actors' followers, number of users' friends, and number of a users' followers were $\log (x+1)$ transformed. Cell entries are regression coefficients with associated standard errors in parentheses. ${ }^{*} p<.05$ 
Table 3.2: Ordinal logistic regression models predicting the sentiment of the comments on the shared tweets using SVM (Conservative users)

\begin{tabular}{llllll}
\hline Variable & All Messages & Media & Journalists & $\begin{array}{l}\text { Politicians } \\
\text { (No Trump) }\end{array}$ & $\begin{array}{l}\text { Politicians } \\
\text { (Incl. Trump) }\end{array}$ \\
\hline Source (Out-group) & $-.48^{*}(.01)$ & $-.23^{*}(.01)$ & $-.38^{*}(.01)$ & $-.77^{*}(.01)$ & $-.77^{*}(.01)$ \\
Num. Followers (actor) & $.02^{*}(.00)$ & $.03^{*}(.00)$ & $.00(.00)$ & $.02^{*}(.00)$ & $.02^{*}(.00)$ \\
Num. Friends (user) & $-.02^{*}(.00)$ & $-.00(.01)$ & $-.03^{*}(.01)$ & $-.03^{*}(.01)$ & $-.03^{*}(.01)$ \\
Num. Followers (user) & $.02^{*}(.00)$ & $.02^{*}(.00)$ & $.02^{*}(.00)$ & $.03^{*}(.01)$ & $.03^{*}(.01)$ \\
Ideo. Extrimity (actor) & $.26^{*}(.02)$ & $.32^{*}(.03)$ & $.13^{*}(.03)$ & $.45^{*}(.05)$ & $.45^{*}(.05)$ \\
Out. Elites Followed & $.00^{*}(.00)$ & $.00^{*}(.00)$ & $.00^{*}(.00)$ & $.00^{*}(.00)$ & $.00^{*}(.00)$ \\
Negative | Neutral & $-.56^{*}(.06)$ & $-.16(.09)$ & $-.79^{*}(.11)$ & $-.68^{*}(.14)$ & $-.68^{*}(.14)$ \\
Neutral | Positive & $-.51^{*}(.06)$ & $-.11(.09)$ & $-.74^{*}(.11)$ & $-.63^{*}(.14)$ & $-.63^{*}(.14)$ \\
Controlling for Time & Yes & Yes & Yes & Yes & Yes \\
Controlling for Topic & Yes & Yes & Yes & Yes & Yes \\
\hline
\end{tabular}

Note: Number of actors' followers, number of users' friends, and number of a users' followers were $\log (\mathrm{x}+1)$ transformed. Cell entries are regression coefficients with associated standard errors in parentheses. ${ }^{*} p<.05$

Table 3.3: Ordinal logistic regression models predicting the sentiment of the comments on the shared tweets using Ensemble (Liberal users)

\begin{tabular}{lllllll}
\hline Variable & All Messages & Media & Journalists & $\begin{array}{l}\text { Politicians } \\
\text { (No Trump) }\end{array}$ & $\begin{array}{l}\text { Politicians } \\
\text { (Incl. Trump) }\end{array}$ & Trump \\
\hline Source (Out-group) & $-.62^{*}(.01)$ & $-.10^{*}(.02)$ & $-.33^{*}(.01)$ & $-.74^{*}(.01)$ & $-.91^{*}(.01)$ & $-.98^{*}(.01)$ \\
Num. Followers (actor) & $.04^{*}(.00)$ & $.02^{*}(.00)$ & $-.01(.00)$ & $.00(.01)$ & $.06^{*}(.00)$ & - \\
Num. Friends (user) & $-.00(.00)$ & $-.02(.01)$ & $-.01(.01)$ & $-.03^{*}(.01)$ & $.01(.00)$ & $.02^{*}(.00)$ \\
Num. Followers (user) & $.01^{*}(.00)$ & $.03^{*}(.01)$ & $.01(.00)$ & $.01(.01)$ & $.00(.00)$ & $-.00(.00)$ \\
Ideo. Extrimity (actor) & $-.41^{*}(.01)$ & $-.12^{*}(.03)$ & $-.11^{*}(.02)$ & $-.77^{*}(.04)$ & $-.79^{*}(.04)$ & - \\
Out. Elites Followed & $.00^{*}(.00)$ & $.00(.00)$ & $.00^{*}(.00)$ & $.00^{*}(.00)$ & $.00^{*}(.00)$ & $.00^{*}(.00)$ \\
Negative | Neutral & $-.41^{*}(.05)$ & $-.26(.17)$ & $-1.07^{*}(.14)$ & $-1.33^{*}(.14)$ & $-.35^{*}(.06)$ & $-.99^{*}(.07)$ \\
Neutral | Positive &.$- .34^{*}(.05)$ & $-.19(.17)$ & $-1.00^{*}(.14)$ & $-1.27^{*}(.14)$ & $-.29^{*}(.06)$ & $-.92^{*}(.07)$ \\
Controlling for Time & Yes & Yes & Yes & Yes & Yes & Yes \\
Controlling for Topic & Yes & Yes & Yes & Yes & Yes & Yes \\
\hline
\end{tabular}

Note: Number of actors' followers, number of users' friends, and number of users' followers were $\log (\mathrm{x}+1)$ transformed. Cell entries are regression coefficients with associated standard errors in parentheses. ${ }^{*} p<.05$ 
Table 3.4: Ordinal logistic regression models predicting the sentiment of the comments on the shared tweets using Ensemble (Conservative users)

\begin{tabular}{llllll}
\hline Variable & All Messages & Media & Journalists & $\begin{array}{l}\text { Politicians } \\
\text { (No Trump) }\end{array}$ & $\begin{array}{l}\text { Politicians } \\
\text { (Incl. Trump) }\end{array}$ \\
\hline Source (Out-group) & $-.41^{*}(.01)$ & $-.20^{*}(.01)$ & $-.34^{*}(.01)$ & $-.67^{*}(.01)$ & $-.67^{*}(.01)$ \\
Num. Followers (actor) & $.02^{*}(.00)$ & $.03^{*}(.00)$ & $-.00(.00)$ & $.03^{*}(.00)$ & $.03^{*}(.00)$ \\
Num. Friends (user) & $-.02^{*}(.00)$ & $-.01(.01)$ & $-.02^{*}(.01)$ & $-.03^{*}(.01)$ & $-.03^{*}(.01)$ \\
Num. Followers (user) & $.02^{*}(.00)$ & $.02^{*}(.00)$ & $.01^{*}(.00)$ & $.02^{*}(.01)$ & $.02^{*}(.01)$ \\
Ideo. Extrimity (actor) & $.24^{*}(.02)$ & $.34^{*}(.03)$ & $.10^{*}(.03)$ & $.35^{*}(.05)$ & $.35^{*}(.05)$ \\
Out. Elites Followed & $.00^{*}(.00)$ & $.00(.00)$ & $.00^{*}(.00)$ & $.00^{*}(.00)$ & $.00^{*}(.00)$ \\
Negative | Neutral & $-.46^{*}(.06)$ & $-.10(.09)$ & $-.75^{*}(.11)$ & $-.59^{*}(.14)$ & $-.59^{*}(.14)$ \\
Neutral | Positive & $-.38^{*}(.06)$ & $-.02(.09)$ & $-.67^{*}(.11)$ &.$- .52^{*}(.14)$ &.$- .52^{*}(.14)$ \\
Controlling for Time & Yes & Yes & Yes & Yes & Yes \\
Controlling for Topic & Yes & Yes & Yes & Yes & Yes \\
\hline
\end{tabular}

Note: Number of actors' followers, number of users' friends, and number of users' followers were $\log (\mathrm{x}+1)$ transformed. Cell entries are regression coefficients with associated standard errors in parentheses. ${ }^{*} p<.05$ 


\section{Ordinal logistic regression models predicting the sentiment of the comments on the shared tweets including moderates}

Table 4.1: Ordinal logistic regression models predicting the sentiment of the comments on the shared tweets including moderates (Liberal users)

\begin{tabular}{lllllll}
\hline Variable & All Messages & Media & Journalists & $\begin{array}{l}\text { Politicians } \\
\text { (No Trump) }\end{array}$ & $\begin{array}{l}\text { Politicians } \\
\text { (Incl. Trump) }\end{array}$ & Trump \\
\hline Source (Out-group) & $-.58^{*}(.00)$ & $.01(.01)$ & $-.21^{*}(.01)$ & $-.72^{*}(.01)$ & $-1.06^{*}(.01)$ & $-1.21^{*}(.01)$ \\
Num. Followers (actor) & $.03^{*}(.00)$ & $.03^{*}(.00)$ & $-.02^{*}(.00)$ & $-.00(.00)$ & $.06^{*}(.00)$ & - \\
Num. Friends (user) & $-.02^{*}(.00)$ & $-.01(.01)$ & $-.02^{*}(.00)$ & $-.05^{*}(.01)$ & $-.02^{*}(.00)$ & $-.01(.00)$ \\
Num. Followers (user) & $.06^{*}(.00)$ & $.05^{*}(.00)$ & $.03^{*}(.00)$ & $.06^{*}(.01)$ & $.07^{*}(.00)$ & $.07^{*}(.00)$ \\
Ideo. Extrimity (actor) & $-.69^{*}(.01)$ & $.05^{*}(.03)$ & $-.27^{*}(.02)$ & $-.82^{*}(.04)$ & $-1.02^{*}(.04)$ & - \\
Out. Elites Followed & $.00^{*}(.00)$ & $.00(.00)$ & $.00^{*}(.00)$ & $.00(.00)$ & $-.00(.00)$ & $-.00^{*}(.00)$ \\
Negative | Neutral & $.14^{*}(.04)$ & $.76^{*}(.11)$ & $-.27^{*}(.10)$ & $-.80^{*}(.12)$ & $.23^{*}(.06)$ & $-.09(.06)$ \\
Neutral | Positive & $.23^{*}(.04)$ & $.86^{*}(.11)$ & $-.17(.10)$ & $-.71^{*}(.12)$ & $.33^{*}(.06)$ & $.01(.06)$ \\
Controlling for Time & Yes & Yes & Yes & Yes & Yes & Yes \\
Controlling for Topic & Yes & Yes & Yes & Yes & Yes & Yes \\
\hline
\end{tabular}

Note: Number of actors' followers, number of users' friends, and number of users' followers were $\log (x+1)$ transformed. Cell entries are regression coefficients with associated standard errors in parentheses. ${ }^{*} p<.05$

Table 4.2: Ordinal logistic regression models predicting the sentiment of the comments on the shared tweets including moderates (Conservative users)

\begin{tabular}{llllll}
\hline Variable & All Messages & Media & Journalists & $\begin{array}{l}\text { Politicians } \\
\text { (No Trump) }\end{array}$ & $\begin{array}{l}\text { Politicians } \\
\text { (Incl. Trump) }\end{array}$ \\
\hline Source (Out-group) & $-.51^{*}(.01)$ & $-.25^{*}(.01)$ & $-.36^{*}(.01)$ & $-1.09^{*}(.01)$ & $-1.09^{*}(.01)$ \\
Num. Followers (actor) & $.02^{*}(.00)$ & $.03^{*}(.00)$ & $-.02^{*}(.00)$ & $.02^{*}(.00)$ & $.02^{*}(.00)$ \\
Num. Friends (user) & $-.03^{*}(.00)$ & $-.00(.00)$ & $-.03^{*}(.00)$ & $-.04^{*}(.01)$ & $-.04^{*}(.01)$ \\
Num. Followers (user) & $.04^{*}(.00)$ & $.03^{*}(.00)$ & $.03^{*}(.00)$ & $.06^{*}(.00)$ & $.06^{*}(.00)$ \\
Ideo. Extrimity (actor) & $.17^{*}(.01)$ & $.18^{*}(.02)$ & $.18^{*}(.01)$ & $.17^{*}(.04)$ & $.17^{*}(.04)$ \\
Out. Elites Followed & $.00^{*}(.00)$ & $.00^{*}(.00)$ & $.00^{*}(.00)$ & $.00^{*}(.00)$ & $.00^{*}(.00)$ \\
Negative | Neutral & $.29^{*}(.04)$ & $.68^{*}(.06)$ & $-.07(.07)$ & $.01(.10)$ & $.01(.10)$ \\
Neutral | Positive & $.42^{*}(.04)$ & $.81^{*}(.06)$ & $.06(.07)$ & $.10(.10)$ & $.10(.10)$ \\
Controlling for Time & Yes & Yes & Yes & Yes & Yes \\
Controlling for Topic & Yes & Yes & Yes & Yes & Yes \\
\hline
\end{tabular}

Note: Number of actors' followers, number of users' friends, and number of users' followers were $\log (\mathrm{x}+1)$ transformed. Cell entries are regression coefficients with associated standard errors in parentheses. ${ }^{*} p<.05$

\section{$5 \quad$ Ingroup and outgroup sharing patterns by elite type}

In Figure 2 of the paper we show a large sharing echo chamber as it comes to messages from elite accounts: ordinary users are substantially more likely to share tweets from ingroup than outgroup elites. Additionally, we also show a substantive sentiment echo chamber: they are also more likely to add a negative commentary when quoting a tweet from an outgroup elite than an ingroup elite. In this SI section we show how these 
pattern hold for the different types of elite groups we study (politicians, media, and journalists), as well as for elites of different ideology (liberal $v$. conservative).

In Figure 5.1 below we show that no matter to which actor type we look at, and from which ideology, ordinary users are more likely to share tweets from ingroup accounts. Descriptively, we see the difference between ingroup and outgroup sharing to be slightly more pronounced among liberals elites (so among conservative users), but the general ingroup-outgroup divide is common across elite type and ideology.

Figure 5.1: How often the tweets of different elite actors (and of different ideology) are shared by ingroup $v$. outgroup ordinary users

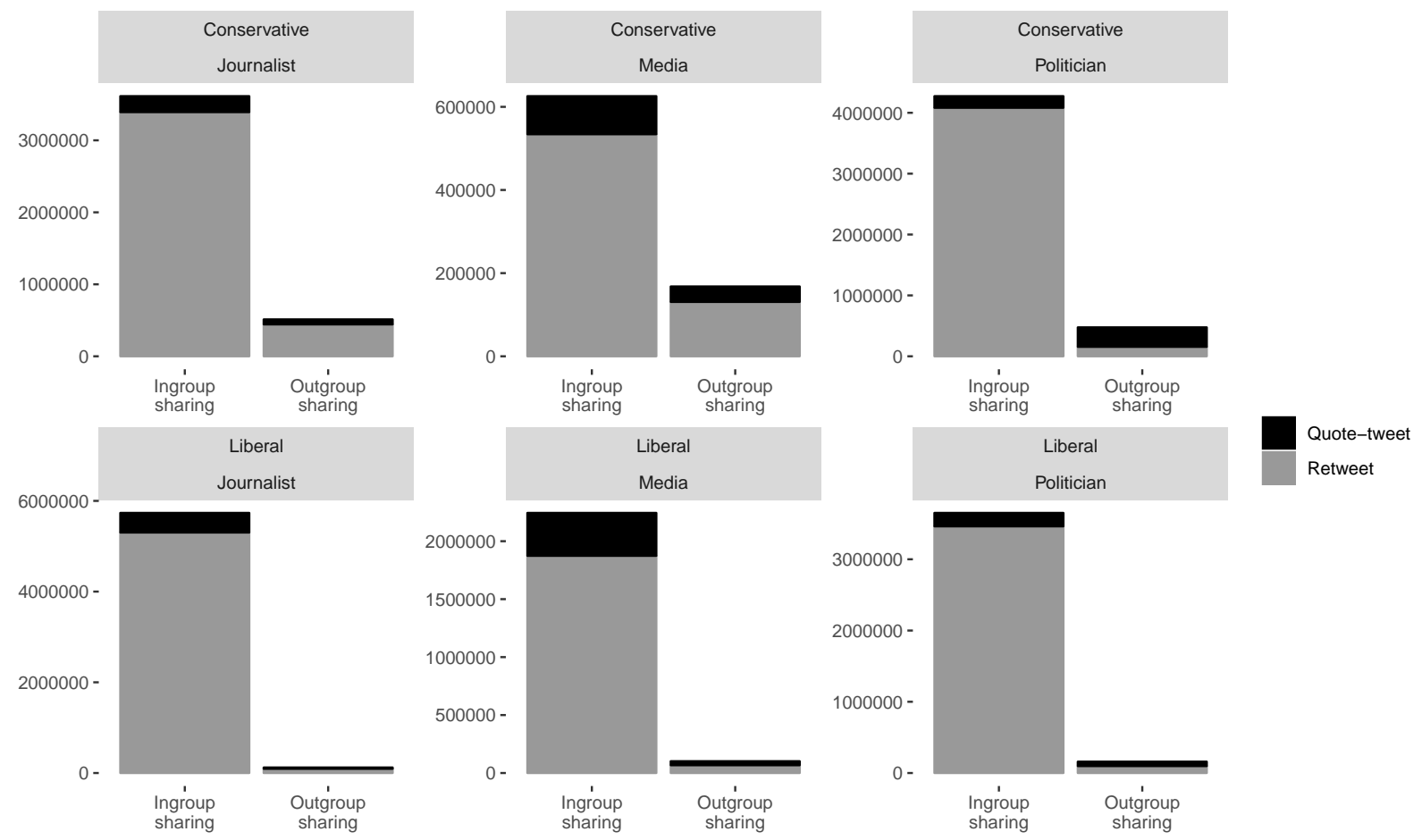

Then, in Figure 5.2 we zoom in on the quote tweets to show how often ordinary users decide to add a negative (or positive) commentary to tweets from the different types of elites. The general pattern is also consistent across elite type: users are more likely to add a negative comment when quoting tweets from outgroup rather than ingroup elites. Although the pattern is clearly more pronounced when looking at politicians rather than media organizations and pundits. 
Figure 5.2: How often the tweets of different elite actors (and of different ideology) are shared by ingroup $v$. outgroup ordinary users

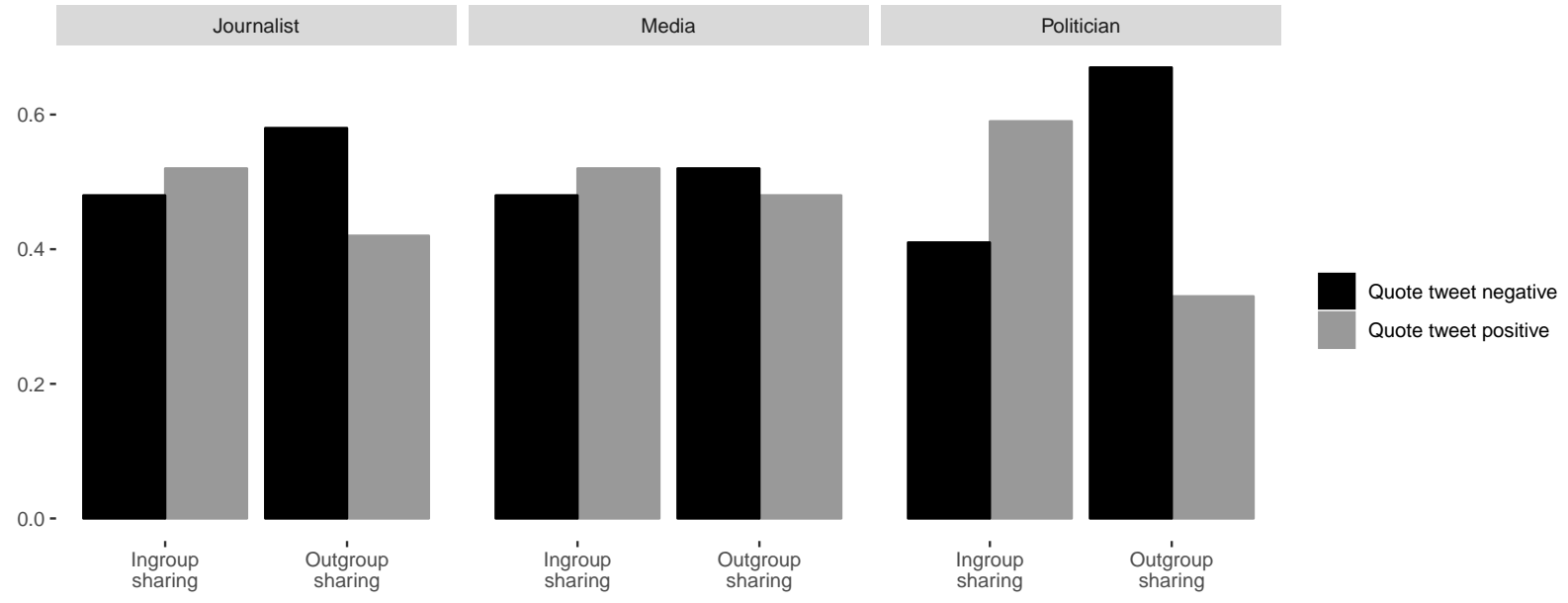

\section{Ingroup sharing and ideological extremity of the actors}

In the paper we show that the sample of Twitter users interested in U.S. politics we study overwhelmingly share ingroup rather than outgroup elite content from politicians, pundits, and the media (Figure 2). However, readers may be concerned that the high levels of ingroup sharing shown in the paper are driven by the users in our sample mostly engaging and sharing content from extreme elite accounts.

Figure 6.1: Ingroup sharing of tweets from elite accounts as a function of their ideological extremity.

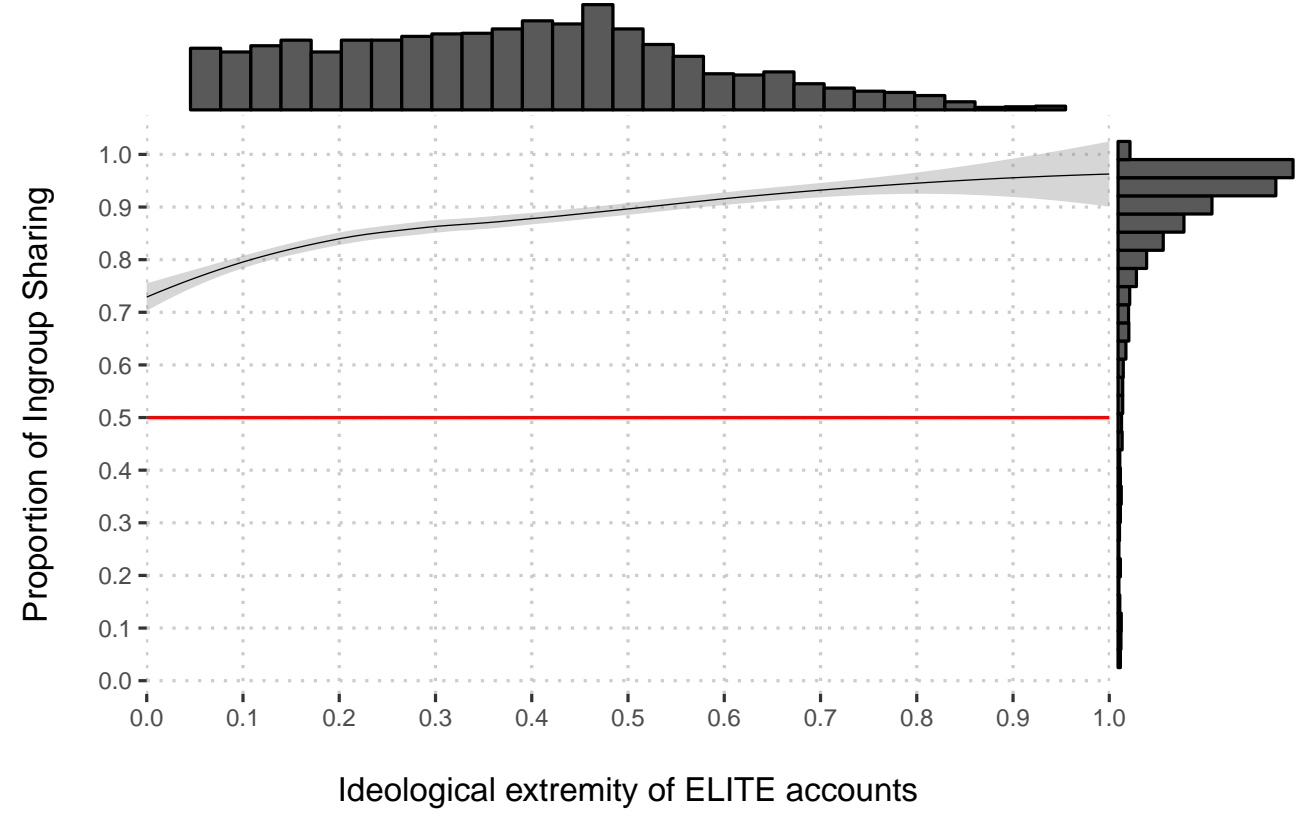


In Figure 6.1 we show how often tweets from elite accounts that we classified as liberal or conservative are shared by users of the same ideological liberal-conservative group (proportion of ingroup sharing). We folded and standardized (between 0 and 1) the ideology scores of the elite accounts in order to create an ideological extremity measure. In this new measure, very moderate liberal and conservative elite accounts have a value close to 0 , and very extreme liberal and conservative elite accounts have values close to 1 . The figure shows that most elite accounts have a relatively moderate ideological extremity score between 0 and 0.5 (see histogram at the top of the figure). We also observe that ingroup sharing is already very high among these moderate liberal and conservative elite accounts. On average, ingroup users are responsible for at least $70 \%$ of the shares of tweets from these accounts. So although the proportion of ingroup sharing is even higher for elite accounts with a very high ideological extremity score, overall we see high levels of ingroup sharing across the board. These results indicate that ingroup sharing is an extended pattern no matter the extremity of the source. 


\section{Ingroup sharing and ideological extremity of the users}

Similarly to what we voiced in the previous section, readers may also be concerned about the overall high levels of in-group sharing shown in the paper to be driven by the messaging activity of a small group of extreme users that mostly follow in-group elite accounts. In Figure 7.1 we followed the same strategy described in the previous section to measure the ideological extremity of the ordinary users we classified as liberals and conservatives. Those with a lower score follow more out-group accounts on Twitter. We observe that the proportion of in-group sharing (proportion of shared tweets from an in-group rather than an out-group elite) is already quite high among the most moderate liberal and conservative users (around $70 \%$ ), and that those users with a medium ideological extremity score (the largest group, as shown in the histogram on the top of the figure) share in-group content at a similar rate (around 90\%) than those with a high score. All and all, these results indicate that high levels of in-group sharing is common among all partisan users on Twitter.

Figure 7.1: Proportion of ingroup sharing of tweets from elite accounts as a function of their ideological extremity.

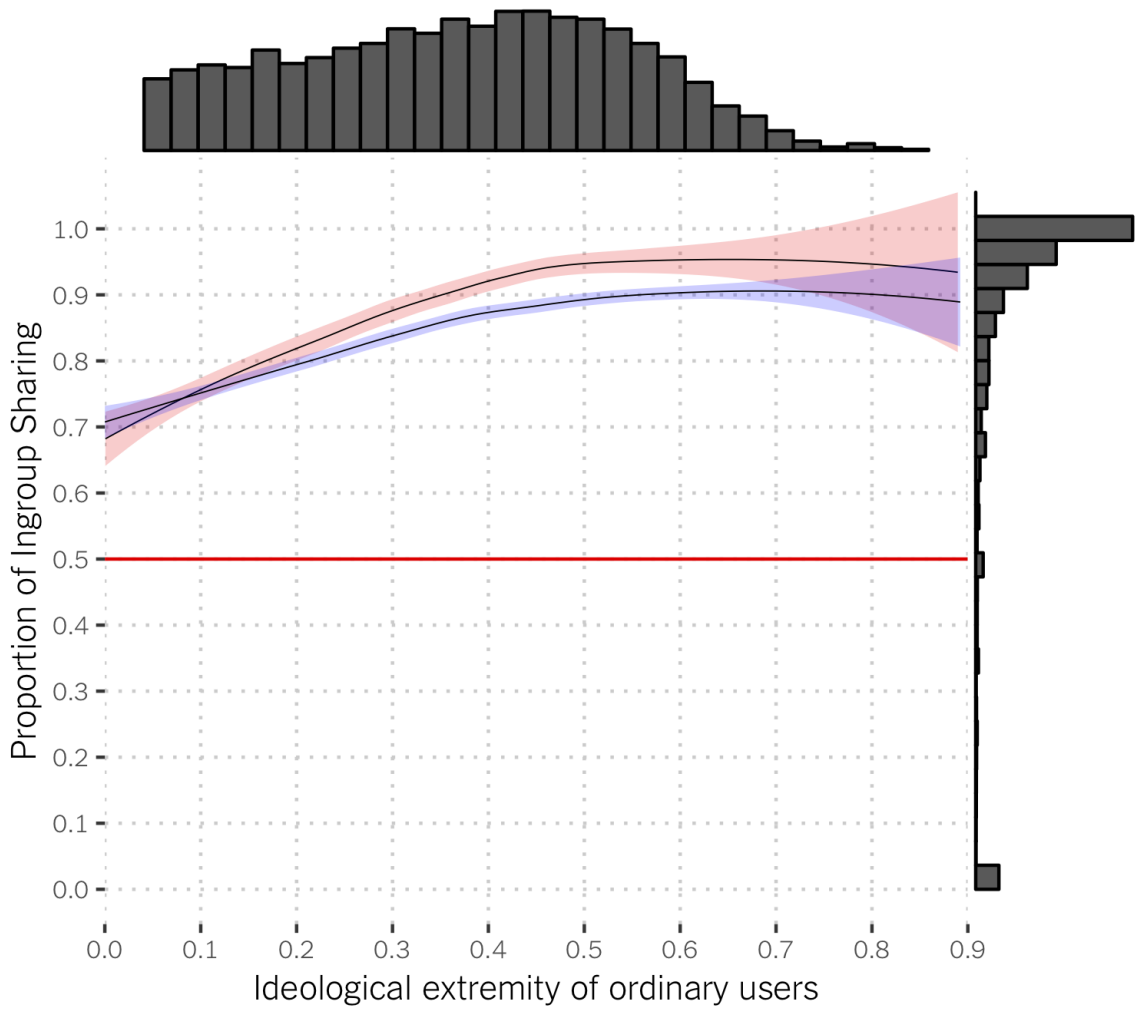

Conservative

Liberal 


\section{Sentiment classifier}

First we randomly sampled about 9,000 messages from our full dataset of quote tweets, and research assistants manually coded them for whether the quote was negative, neutral or positive towards the original elite tweet. The agreement between coders was satisfactory, Krippendorff's alpha $=.816$.

Then we used this annotated dataset to train the following 5 types of machine learning models predicting whether the commentaries were positive, neutral, or negative (multi-class models): (a) a Decision tree (TREE), (b) a K-neighbors model, (c) a Support vector machine, (d) a majority-based ensemble model that took into account the output of the three previous ones, and (e) a four-layer Convolutional Neural Net. For training (a), (b), (c), and (d), we transformed all text to lowercase, removed stopwords, and lemmatized the remaining tokens to finally create a TF-IDF matrix that we used as model input. For the CNN model, we transformed all text to lower case and used 300-dimension GloVe embeddings as inputs.

We tested the accuracy of each algorithm using 5 -fold crossvalidation and a 80/70 train-test split. In Figure 8.1 we show the overall accuracy of each of the five classifiers. The CNN proved to be the most accurate one overall. Moreover, we also assessed the ability of each classifier to predict each target category in particular. In Figure 8.2 we show the precision, recall, and f-score at the target class level for each of the trained classifiers. The horizontal red lines indicate the proportion of quote tweets labeled as being about each category, which serve as a key reference for judging the performance of the models: if we were to classify tweets at random, at least we would perform as well as the red line, so we should aim for the performance of our classifiers to be above the red line. We observe the CNN to score among the highest fscores for the negative and positive categories, and to do much better than the other classifiers in predicting the neutral category. For this reason we decided to used the CNN classifier to predict the tone of all quote tweets in our dataset.

Figure 8.1: Overall out-of-sample accuracy of the 5 machine learning classifiers trained to predict the tone of the quote tweets.

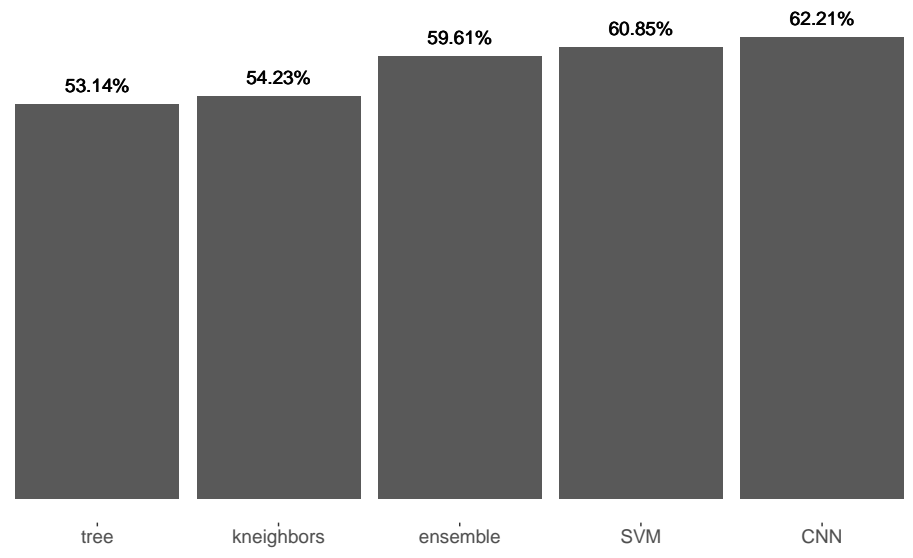


Figure 8.2: Target-class-level precision, recall and f-score for the 5 machine learning classifiers trained to predict the tone of the quote tweets.

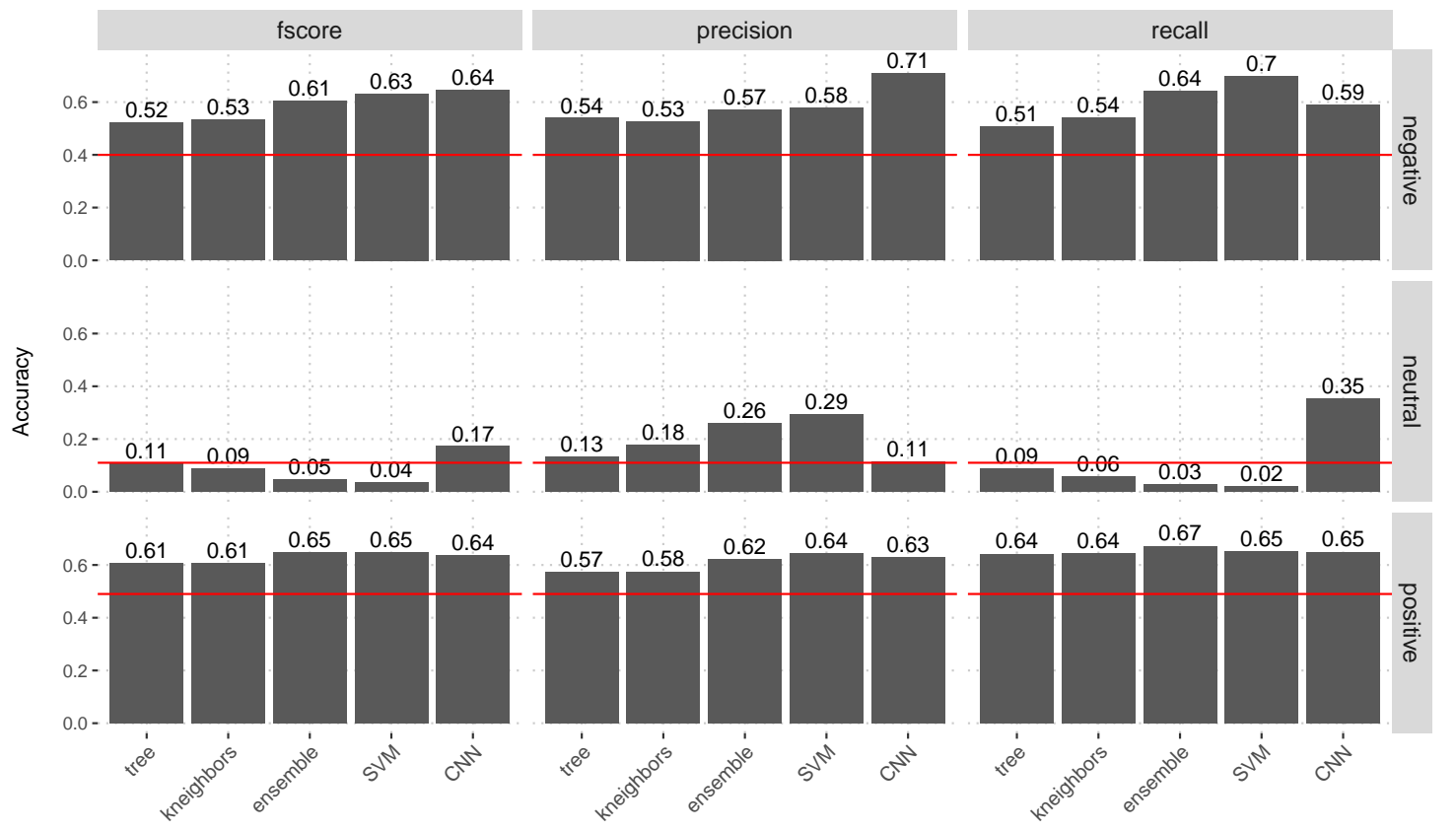

\section{Topic classifier}

In this section we explain how we automatically coded the topic of the content of the original tweets from elite accounts that we study. Given the large number of tweets, manual coding was not practical for the full corpus. Instead, we trained a machine learning model (a Convolutional Neural Net (CNN)) predicting whether each tweet discussed one of the 20 topics of the Comparative Agendas Project (CAP) (Baumgartner and Jones, 2010), ${ }^{1}$ a comprehensive and widely used classification for studying political agendas, plus a nonpolicy-issue category reserved for tweets that did not address any substantive policy area, such as tweets commemorating holidays. ${ }^{2}$ Similar to Kim (2014), we trained a three-layer CNN. Figure 9.1 illustrates the architecture used to identify CAP-topics. We next describe our two main model architectures, and then proceed to describe in detail our training data-sets and valdation scheme. This model was originally trained and validated for another of our projects in which we needed to predict the topic of tweets sent by state legislators in the United States around the same time period, so we are confident that it does a good job at predicting the topic of tweets sent by political elites.

First, we represented each word in a given sentence as a 300-dimension word- embedding (a vector that ideally represents an integration of each word's meaning and context/position in the text as dense features for further analysis) (Terechshenko et al., 2020). We obtained the models used to produce word-embeddings by finetuning a pretrained Word2Vec model for an additional 10 epochs (Mikolov et al., 2013), to which we had first added all unique new vocabulary present in our training datsets as well as in the tweets to which we wanted to apply the resulting model. ${ }^{3}$ This results in a three-dimensional matrix $(n \times k \times d)$ that is used as our primary model input, where $n$ is the maximum word length for all training documents, $k$ is the size

\footnotetext{
${ }^{1}$ We excluded Culture topics from the 21 topics of the CAP codebook because in initial tests we saw very low numbers of tweets about this topic and the topic was not very relevant for the analysis carried out here.

${ }^{2}$ See Table 9.3 for a list of topics.

${ }^{3}$ We used the python Gensim word2vec model and methods, and GloVe pretrained embeddings: Common Crawl (42B tokens, $1.9 \mathrm{M}$ vocab, uncased, $300 \mathrm{~d}$ vectors, $1.75 \mathrm{~GB}$ download).
} 
of the embedding (300), and $d$ is the number of documents to pass through to the CNN.

Figure 9.1: Architecture of the Convolutional Neural Net predicting the policy topics discussed in tweets by state legislators.

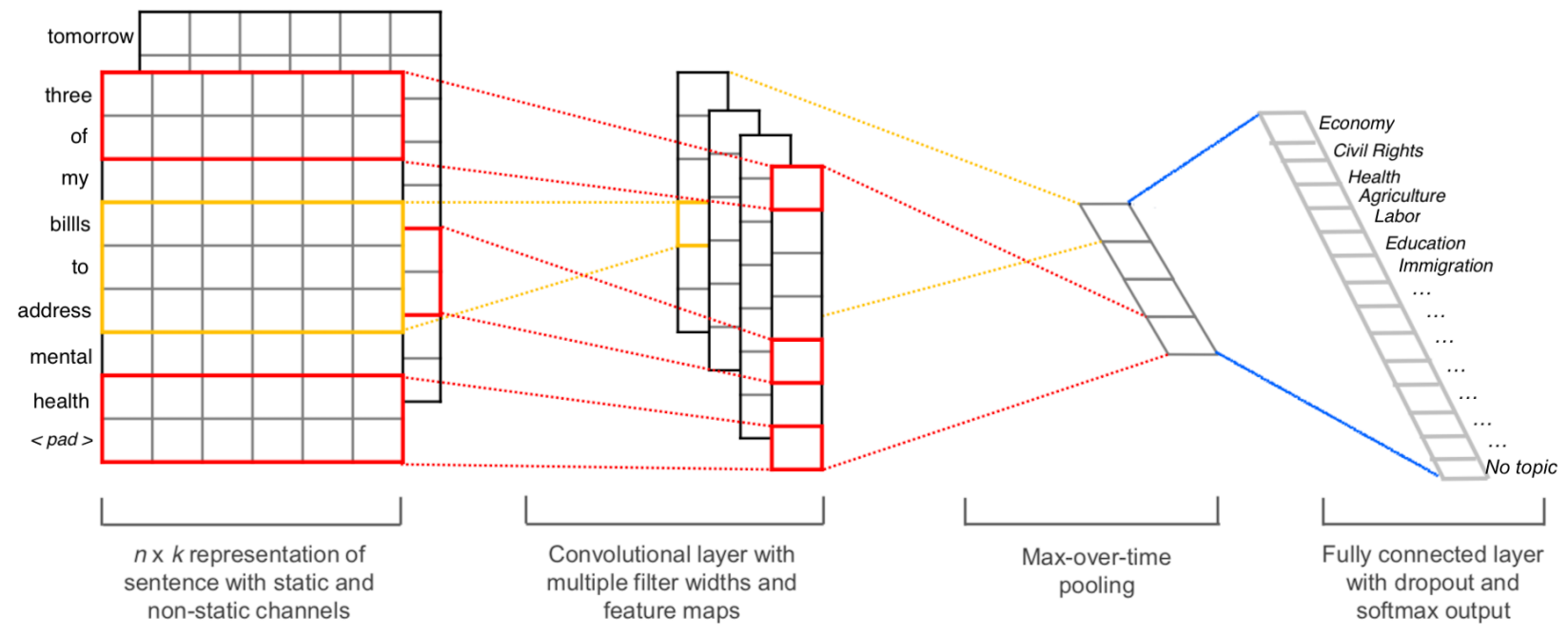

The CNN that comprises our second model (the model used to classify the CAP topic) has three convolutional layers of different sizes, each processing 3-, 4-, and 5-word embeddings at a time, and so producing hidden layers of different sizes. These hidden layers are joined into a single vector for each document by max-pooling the weights in each word-vector. The last stage of the CNN is comprised of a fully connected layer mapping the previous max-pooled vector to the 21 CAP issue classes (20 policy areas plus the "nonpolicy/not-relevant" class). We employ a cross-entropy loss function; gradient optimization is performed via adaptive moment estimation (Kingma and $\mathrm{Ba}, 2015$ ). We use a batch size of 64 for training the model.

We trained the model with various datasets, assessed the out-of-sample accuracy of each model-dataset pair and selected the best performing model-data pairing to generate topic predictions for tweets sent by political elites in 2018: state legislators from the United States. In our training datasets, each observation (document or tweet) has been coded as belonging to one (mutually exclusive) topic category (or the no-topic one).

We used four datasets, described in Table 9.1. The first one is composed of publicly available data, the second one comes from the replication material of a published study, and the final two have been created/annotated by us for the purpose of this and other studies. In the first dataset (A) we combined all available CAP-labeled datasets for the United States available in the CAP website $(789,004$ observations in total). The second dataset (B) is comprised of 45,394 tweets from Senators who served during the 113th Congress and that were labeled by Russell (2018). The third set (C) consists of 18,088 tweets sent by media accounts and followers of state legislators that we coded according to the CAP classification. The fourth dataset (D) consists of 3,368 tweets sent by the state legislators that we also annotated. ${ }^{4}$ We trained the same CNN model nine times using the following data combinations, with the goal of taking advantage of transfer learning and training more accurate models than simply training the model with the tweets from state legislators that we had coded (so only set D): (1) only set A, (2) only set D, (3) set A and set D, (4) set D and a small sample of set A (1,300 observations), (5) set D and a smaller sample of set A (650 observations), (6) set D and set B, (7) set D and a small sample of set B (1,300 tweets), (8) set D and a smaller sample of set B (650 tweets), (9) set D and set C.

\footnotetext{
${ }^{4} \mathrm{~A}$ total of six coders (research assistants) participated in the annotation of sets $\mathrm{C}$ and $\mathrm{D}$. Two coders annotated the tweets sent by media accounts (C.a): $89 \%$ agreement and 0.7 Cohen's Kappa. Two other coders annotated the tweets sent by followers of state legislators (C.b): 91\% agreement and 0.77 Cohen's Kappa. And finally, a different pair of coders annotated the tweets sent by state legislators (D): $87.1 \%$ agreement and 0.74 Cohen's Kappa.
} 
Table 9.1: Public datasets coded using the CAP 21-issue classification, used for training and testing a classifier predicting Policy Issues in tweets from state legislators.

\begin{tabular}{llrr}
\hline \hline Set & Dataset & \multicolumn{1}{c}{ Time } & \multicolumn{1}{c}{$\mathrm{N}$} \\
\hline \hline & Congressional Quarterly Almanac & $1948-2015$ & 14,444 \\
& New York Times Front Page & $1996-2006$ & 31,034 \\
& New York Times Index & $1946-2014$ & 54,578 \\
& Congressional Bills & $1947-2016$ & 463,762 \\
& Congressional Hearings & $1946-2015$ & 97,593 \\
A & $1948-2011$ & 33,644 \\
& Public Law Titles & $1948-2017$ & 20,928 \\
& Public Laws & $1945-2017$ & 4,294 \\
& Executive Orders & $1985-2016$ & 1,618 \\
& Presidential Veto Rhetoric & $1946-2018$ & 22,289 \\
& State of the Union Speeches & $1948-2016$ & 15,953 \\
& Democratic Party Platform & $1948-2016$ & 19,836 \\
& Republican Party Platform & $1944-2009$ & 9,031 \\
\hline Supreme Court Cases & $2013-2015$ & 45,394 \\
\hline B & Tweets sent by Senators 113th Congress & 2018 & 8,802 \\
\hline \multirow{2}{*}{ C } & Tweets sent by media accounts & 2018 & 9,286 \\
\hline & Tweets sent by followers of state legislators & 2018 & 3,368 \\
\hline D & Tweets sent by state legislators & $1944-2018$ & 855,854 \\
\hline \hline & Total & & \\
& & &
\end{tabular}

Table 9.2: Out of sample accuracy of the nine versions of the CNN model we trained predicting the political topics of the Comparative Agendas Project.

\begin{tabular}{lcc} 
Model version & Test Accuracy & $\begin{array}{c}\text { Test Accuracy } \\
\text { policy tweets }\end{array}$ \\
\hline \hline (6) set D and B & 0.78 & 0.79 \\
(1) set A & 0.73 & 0.73 \\
(3) set D and A & 0.73 & 0.73 \\
(9) set D and C & 0.77 & 0.49 \\
(7) set D and small B & 0.56 & 0.36 \\
(4) set D and small A & 0.55 & 0.32 \\
(8) set D and smaller B & 0.57 & 0.29 \\
(5) set D and smaller A & 0.56 & 0.28 \\
(2) set D & 0.60 & 0.26
\end{tabular}

To assess the performance of these nine versions of the model we split the data used in each case into a train and test set. In Table 9.2 we report the accuracy of the nine versions of the model we trained (based on 3 -fold cross-validation), based on held-out test sets. We assess the test accuracy when predicting all tweets in the test split (Test Accuracy), and also when only predicting the tweets coded as being about one of the policy areas, so after excluding the no-policy tweets (Test accuracy policy tweets). The tweets not related to any policy area represented a large part of the tweets we coded from state legislators (set D) and we wanted to make sure that our model did well at both distinguishing overall policy relevance and at distinguishing between policy areas.

The model trained with the coded tweets by state legislators plus the coded tweets sent by Senators of 
Table 9.3: Class accuracy and f-score for the best performing model

\begin{tabular}{lrrr} 
Policy Area & $\begin{array}{r}\text { Class } \\
\text { Proportion }\end{array}$ & $\begin{array}{r}\text { Test } \\
\text { Accuracy }\end{array}$ & $\begin{array}{r}\text { Test } \\
\text { F-score }\end{array}$ \\
\hline \hline No Policy & 0.48 & 0.74 & 0.82 \\
Govt. Operations & 0.13 & 0.81 & 0.75 \\
Health & 0.06 & 0.80 & 0.73 \\
Economy & 0.05 & 0.74 & 0.76 \\
Education & 0.03 & 0.83 & 0.67 \\
Civil Rights & 0.03 & 0.69 & 0.58 \\
Housing & 0.02 & 0.36 & 0.46 \\
Environment & 0.02 & 0.58 & 0.61 \\
Transportation & 0.02 & 0.73 & 0.68 \\
Agriculture & 0.02 & 0.93 & 0.72 \\
Energy & 0.02 & 0.83 & 0.70 \\
Social Welfare & 0.02 & 0.53 & 0.61 \\
Law \& Crime & 0.02 & 0.67 & 0.48 \\
Intl. Affairs & 0.01 & 0.71 & 0.63 \\
Immigration & 0.01 & 0.92 & 0.92 \\
Public Lands & 0.01 & 0.67 & 0.63 \\
Labor & 0.01 & 0.70 & 0.56 \\
Domestic Commerce & 0.01 & 0.75 & 0.45 \\
Technology & 0.01 & 0.38 & 0.50 \\
Defense & 0.00 & 0.75 & 0.35
\end{tabular}

the 113th Congress returned the best (and very satisfactory) results when predicting out of sample the topic of tweets from state legislators. We hence used this model to generate topic predictions for the tweets sent by the elite accounts in the paper. The test accuracy in both cases is close to $80 \%$ (very high given that the model is predicting 21 topic classes, and that topic overlap is possible in the training set). In table 9.3 we show that the accuracy and f-score (based on the held-out test sets) is very high for all the topic classes, despite most of them being rarely discussed.

To assess the face validity of the model, in Table 9.4 we show the top distinctive text features of the tweets predicted to be about each topic. Reassuringly, the top features seem to be relevant to each topic. 
Table 9.4: Top distinctive features of tweets predicted by the CNN to be about each topic or policy area. Topic Top Features

\begin{tabular}{|c|c|}
\hline No policy issue & thank, great, all, today, so, day, me, one, happy, m, good, time, thanks, join \\
\hline Healthcare & $\begin{array}{l}\text { health, care, maternal, mental, new, day, flu, healthcare, work, get, state, } \\
\text { medicaid, mortality, all }\end{array}$ \\
\hline Gov. Operations & $\begin{array}{l}\text { vote, election, today, day, state, voting, primary, early, all, house, time, } \\
\text { democratic, people }\end{array}$ \\
\hline Intl. Affairs & $\begin{array}{l}\text { russia, russian, putin, right, now, trumps, world, american, dead, peace, } \\
\text { people, says }\end{array}$ \\
\hline Public Lands & $\begin{array}{l}\text { park, state, fire, during, public, thank, wildlife, beautiful, city, confederate, } \\
\text { contained, discussion, grand, heritage, history, land }\end{array}$ \\
\hline Labor & $\begin{array}{l}\text { job, workers, fair, jobs, community, employees, need, work, workforce, } \\
\text { working, youth, according, better }\end{array}$ \\
\hline Law and Crime & $\begin{array}{l}\text { children, gun, violence, families, law, parents, sexual, separated, thank, guns, } \\
\text { people, child, school, community }\end{array}$ \\
\hline Defense & military, veterans, war, one, day, women, state, families, honor, veteran, friend \\
\hline Immigration & $\begin{array}{l}\text { daca, children, border, immigration, immigrants, immigrant, families, } \\
\text { dreamers, policy, parents, detention, migrant, family, stand, trumps }\end{array}$ \\
\hline Domestic Commerce & $\begin{array}{l}\text { harvey, flooding, community, business, small, city, need, local, businesses, } \\
\text { hurricane, many, disaster, state, flood }\end{array}$ \\
\hline Civil Rights & $\begin{array}{l}\text { women, rights, scotus, redistricting, day, voter, case, join, people, court, } \\
\text { families }\end{array}$ \\
\hline Economy & tax, taxes, property, budget, economy, state, tariffs, need, spending \\
\hline Environment & $\begin{array}{l}\text { water, climate, change, earthday, right, air, cleanup, lake, nasa, san, } \\
\text { brownsville, great, mars }\end{array}$ \\
\hline Transportation & transportation, nasa, outhwestair, airlines, future, hearing, bus, get \\
\hline Energy & $\begin{array}{l}\text { energy, gas, oil, solar, texasoilnews, oilandgas, texasoil, txenergy, back, coal, } \\
\text { committee, cpsenergy, nasa, natural, next }\end{array}$ \\
\hline Agriculture & $\begin{array}{l}\text { food, farm, farmers, agriculture, taking, agricultural, bureau, campus, } \\
\text { farming, learning }\end{array}$ \\
\hline Social Welfare & $\begin{array}{l}\text { food, safoodbank, snap, hunger, meals, help, million,free, program, children, } \\
\text { kids, nutritious, summer }\end{array}$ \\
\hline Education & $\begin{array}{l}\text { school, students, education, public, schools, teachers, state, finance, college, } \\
\text { high, teacher, funding, kids }\end{array}$ \\
\hline Technology & $\begin{array}{l}\text { nasa, space, station, mission, astronaut, international, students, media, crew, } \\
\text { launch, satellite, astronauts, awards, contract, earth, internet }\end{array}$ \\
\hline Foreign Trade & $\begin{array}{l}\text { trade, trumps, war, abandons, barrel, beijing, billion, breath, canada, chinese, } \\
\text { cover, currently, deals, economy }\end{array}$ \\
\hline Housing & $\begin{array}{l}\text { housing, affordable, hearing, association, austin, citys, gentrification, losaltos, } \\
\text { meeting, neighborhood, policy, access, aff, affairs }\end{array}$ \\
\hline
\end{tabular}

\section{References}

Baumgartner, Frank R and Bryan D Jones. Agendas and instability in American politics. University of Chicago Press, 2010.

Kim, Yoon. Convolutional neural networks for sentence classification. CoRR, abs/1408.5882, 2014.

Kingma, Diederik P. and Jimmy Ba. Adam: A method for stochastic optimization. In 3rd International 
Conference on Learning Representations, ICLR 2015, San Diego, CA, USA, May 7-9, 2015, Conference Track Proceedings, 2015.

Mikolov, Tomas, Kai Chen, Greg Corrado, and Jeffrey Dean. Efficient estimation of word representations in vector space. In 1st International Conference on Learning Representations, ICLR 2013, Scottsdale, Arizona, USA, May 2-4, 2013, Workshop Track Proceedings, 2013.

Russell, Annelise. Us senators on twitter: Asymmetric party rhetoric in 140 characters. American Politics Research, 46(4):695-723, 2018.

Terechshenko, Zhanna, Fridolin Linder, Vishakh Padmakumar, Fengyuan Liu, Jonathan Nagler, Joshua A. Tucker, and Richard Bonneau. A comparison of methods in political science text classification: Transfer learning language models for politics. Presented at the XXXVII PolMeth Annual Meeting, 2020. 